Supporting Information

\title{
Formation of supramolecular polymers from
}

\section{porphyrin tripods}

Hosoowi Lee, ${ }^{a}$ Dajung Lee, ${ }^{a}$ Inhye Kim, ${ }^{b}$ Eunji Lee, ${ }^{b, *}$ and Woo-Dong Jang ${ }^{a, *}$

aDepartment of Chemistry, Yonsei University, 50 Yonsei-ro, Seodaemoon-Gu, Seoul

03722, Korea

bSchool of Materials Science and Engineering, Gwangju Institute of Science and

Technology (GIST), 123 Cheomdangwagi-ro, Buk-Gu, Gwangju 61005, Korea.I

Corresponding Authors

*Eunji Lee: eunjilee@gist.ac.kr

*Woo-Dong Jang: wdjang@yonsei.ac.kr 




Figure S1. Overlay of the normalized absorption curves of $\mathrm{P}_{\mathrm{Zn}} \mathrm{T}(5.0 \mu \mathrm{M})$ at $435 \mathrm{~nm}$ recorded at different temperature intervals and plotted as a function of temperature.
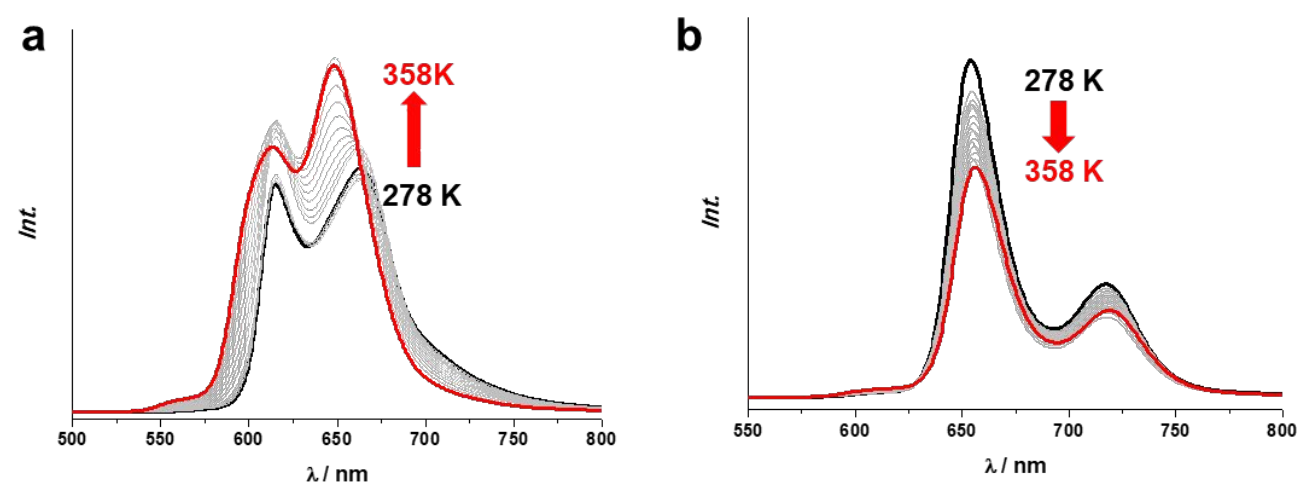

Figure S2. V-T fluorescence spectra of a) $\mathrm{P}_{\mathrm{Zn}} \mathrm{T}(5.0 \mu \mathrm{M})$ and b) $\mathrm{P}_{\mathrm{FB}} \mathrm{T}(1.4 \mu \mathrm{M})$ both in toluene, during heating from 278 to $358 \mathrm{~K}$, measured at $5 \mathrm{~K}$ temperature intervals. 

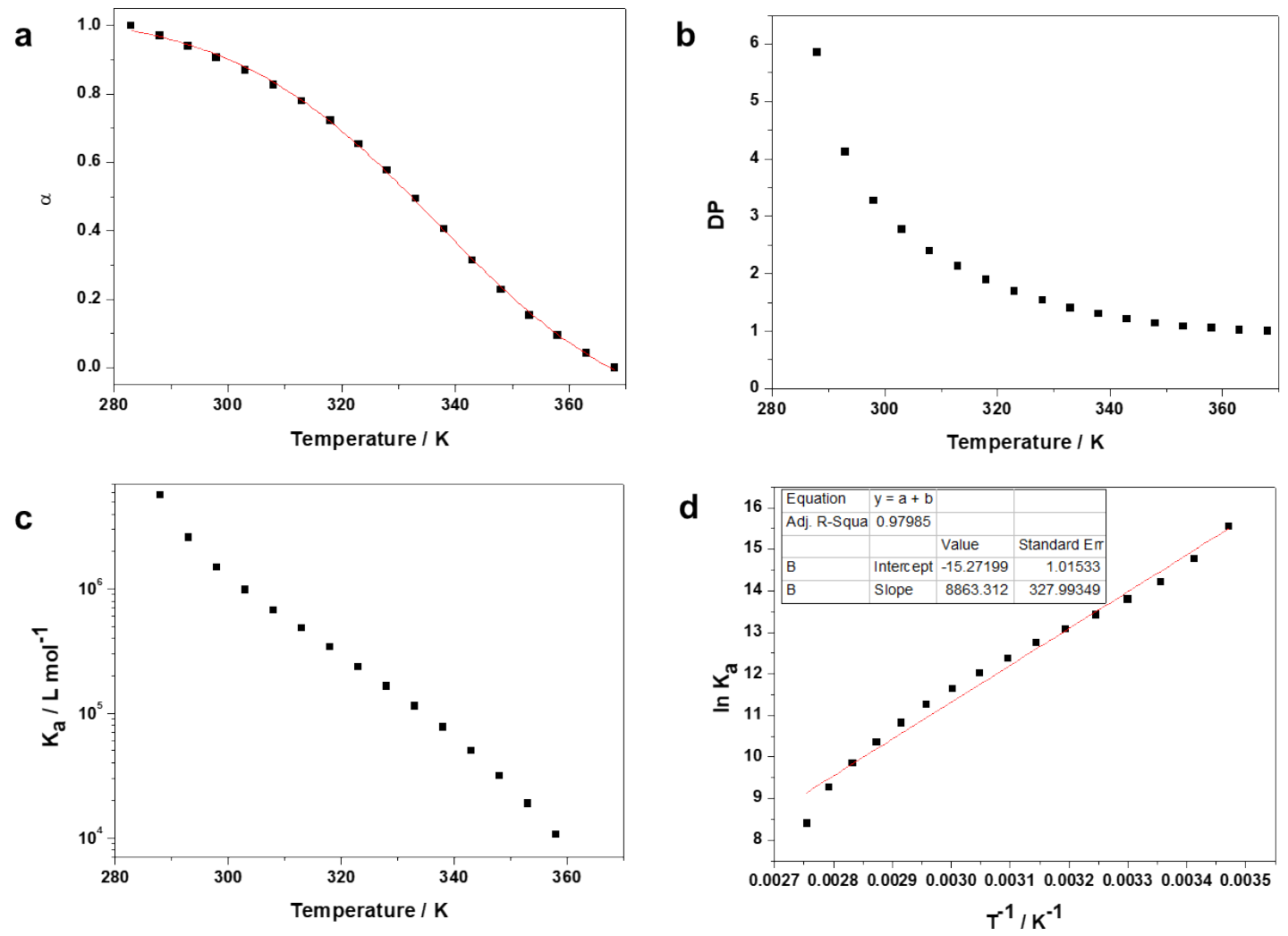

Figure S3. a) temperature-dependent degree of aggregation, $\alpha$, calculated from the absorption at $424 \mathrm{~nm}$ and the corresponding isodesmic non-linear curve fitting, obtained from V-T absoprion spectra of $\mathrm{P}_{\mathrm{Zn}} \mathrm{T}(2.0 \mu \mathrm{M})$ from 368 to $\left.278 \mathrm{~K}, \mathrm{~b}\right)$ numberaverage degree of polymerization , DP, as a function of temperature, and c) elongation aggregation constant, $\mathrm{K}_{\mathrm{a}}$, as a function of temperature and d) van't Hoff plot for thermodynamic parameters. 



Figure S4. AFM images of a) $P_{Z_{n}} T$ and the mixture of $P_{Z_{n}} T$ with b) 0.5 eq. and c) 1.0 eq. of TB in toluene.
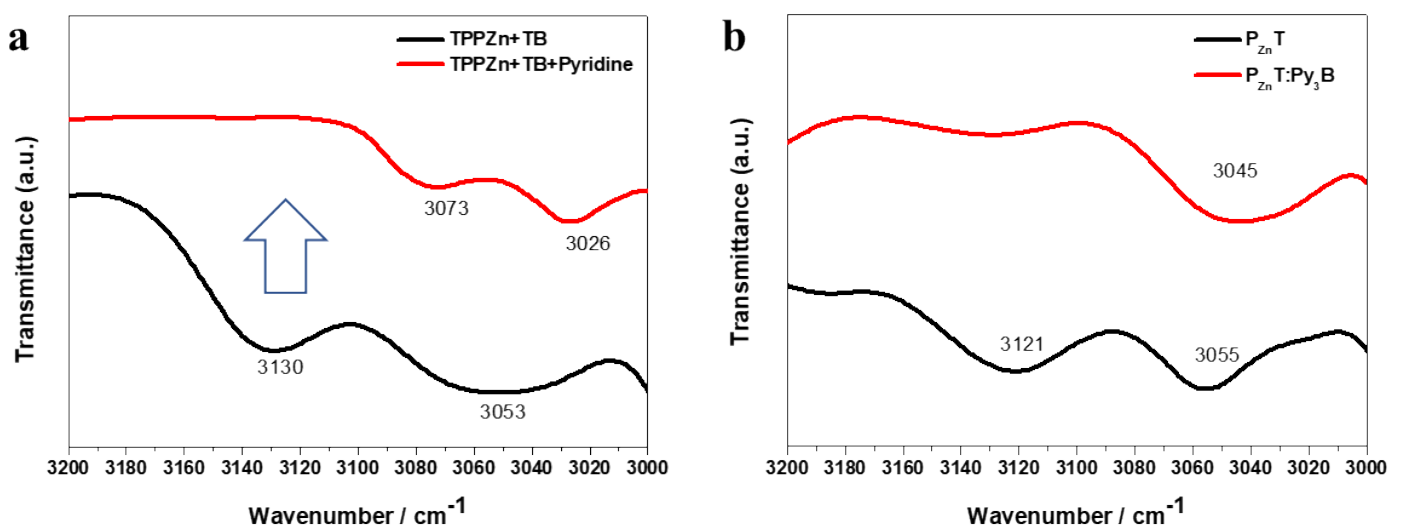

Figure S5. FT-IR spectra of a) ZnTPP with excess of TB (black line) and both TB and pyridine (red line) and $b$ ) $P_{z n} T$ (black line) and $P_{z n} T$ and $P_{z n} T \cdot P_{3} B$ (red line
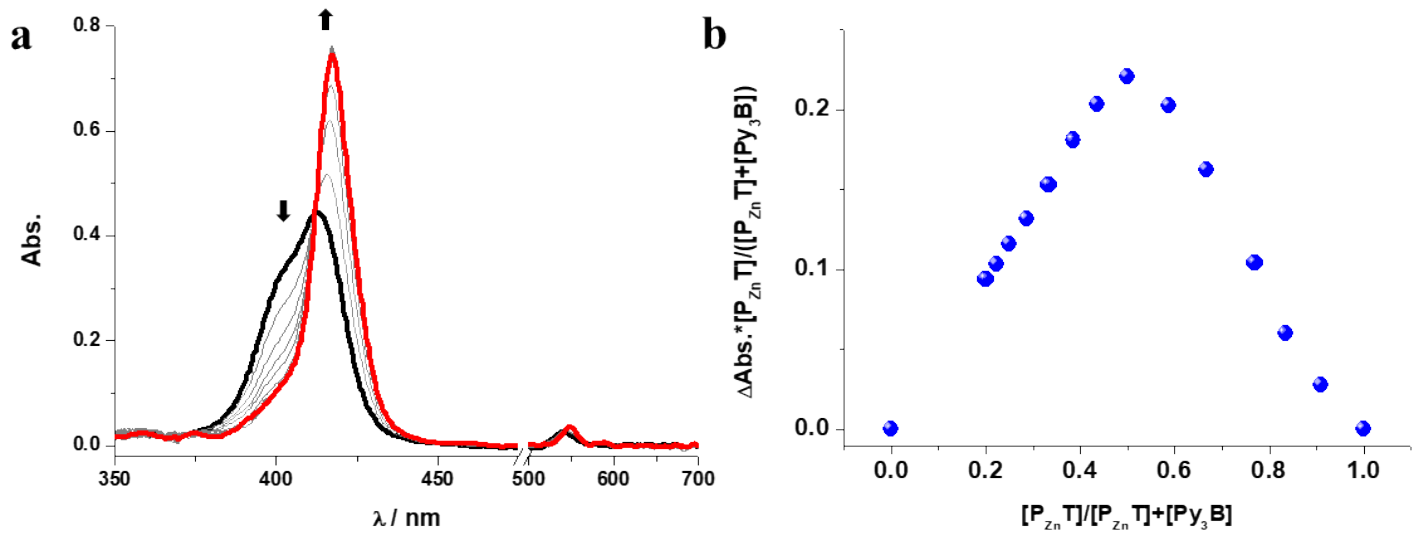
Figure S6. a) Absorption spectra during the titration of $\mathrm{Py}_{3} \mathrm{~B}$ (0-4.0 equiv) to $\mathrm{P}_{\mathrm{Zn}} \mathrm{T}$ (conc. $=2.14 \times 10^{-6} \mathrm{M}$ ) in toluene at $298 \mathrm{~K}$, and b) the Job's plot of $\mathrm{P}_{\mathrm{Zn}} \mathrm{T}$ with $\mathrm{Py}_{3} \mathrm{~B}$, monitored at $429.5 \mathrm{~nm}$. 

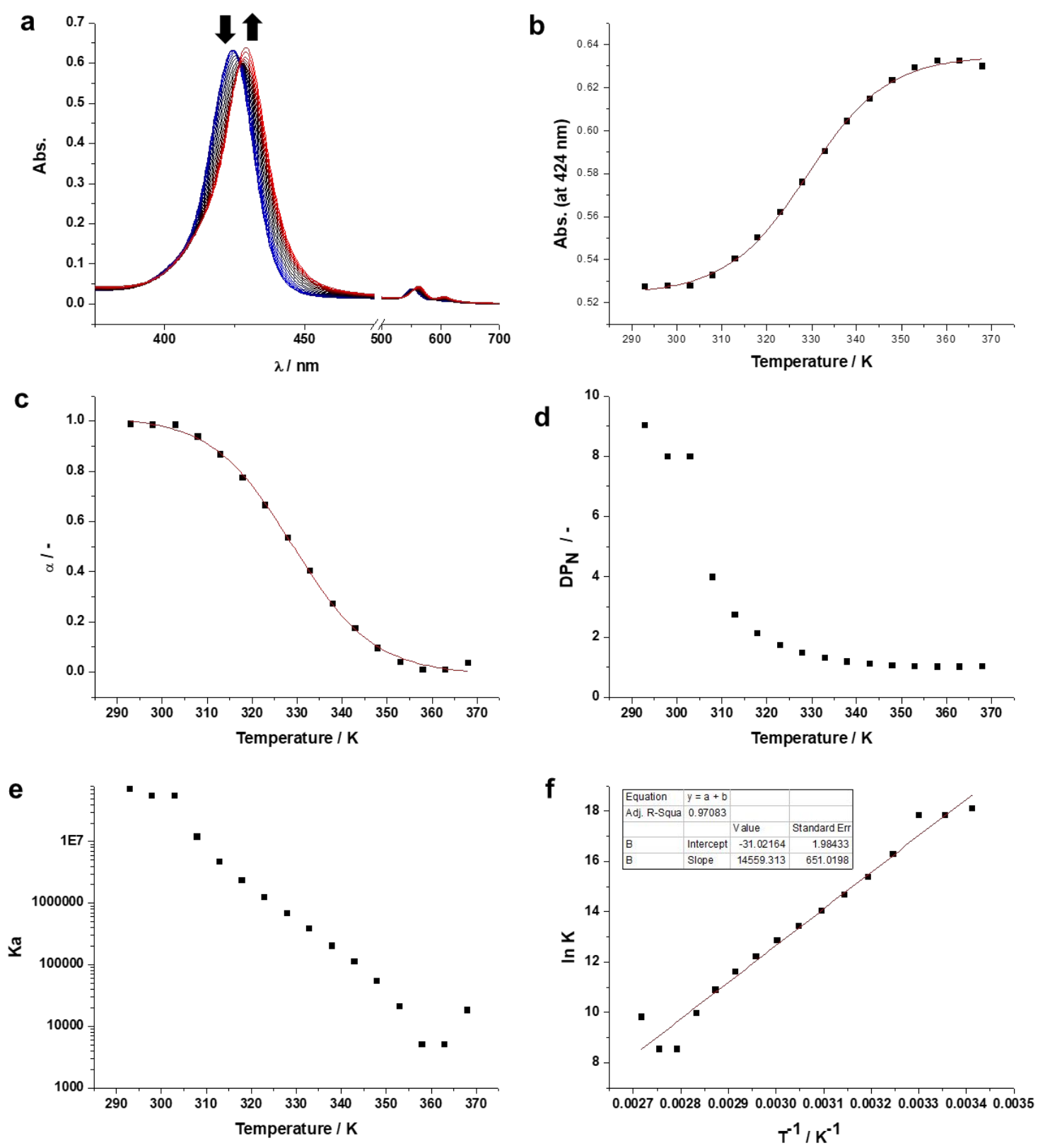

Figure S7. a) V-T spectra of $\mathrm{P}_{\mathrm{Zn}} \mathrm{T} \cdot \mathrm{Py} y_{3} \mathrm{~B}$ from 368 to $293 \mathrm{~K}$, recorded with cooling rate of $1 \mathrm{~K} \mathrm{~min}^{-1}$. b) Temperature-deoebdebt absirotuib cgabges at $424 \mathrm{~nm}$. c) temperaturedependent degree of aggregation, $\alpha$, calculated from the absorption at $424 \mathrm{~nm}$ and the corresponding isodesmic non-linear curve fitting, d) number-average degree of polymerization , DP, as a function of temperature, and e) elongation aggregation constant, $K_{a}$, as a function of temperature and f) van't Hoff plot for thermodynamic parameters. 

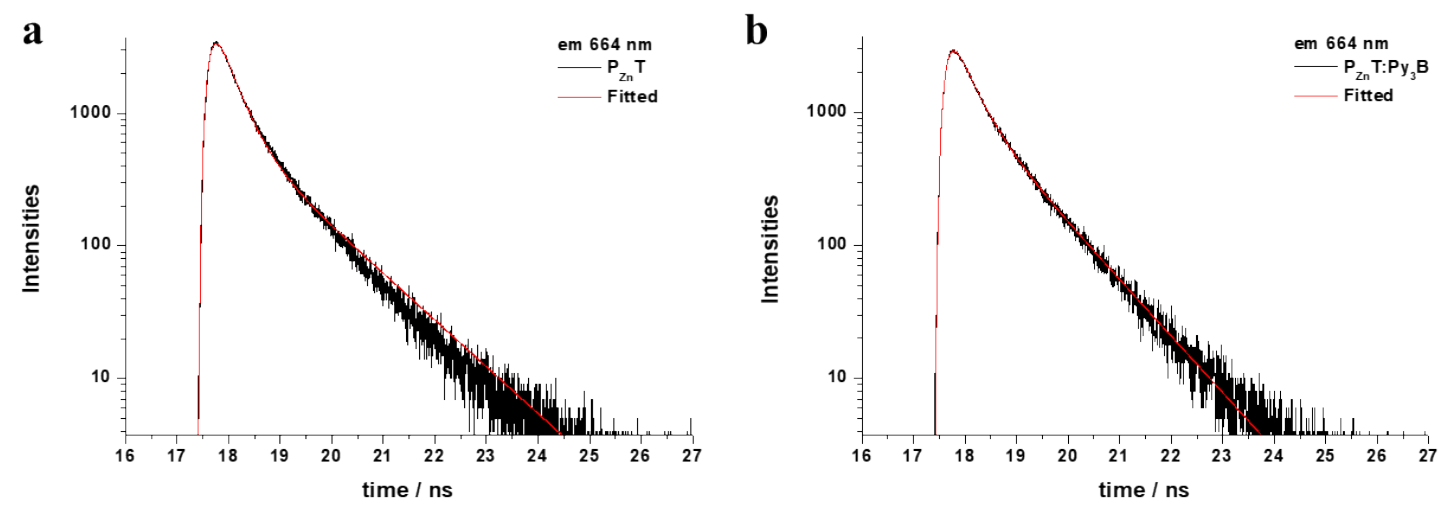

Figure S8. Experimental (black line) and fitted (red line) curves of lifetime decay profiles for a) $\mathrm{P}_{\mathrm{zn}} \mathrm{T}$ and b) $\mathrm{P}_{\mathrm{Zn}} \mathrm{T} \cdot \mathrm{Py}_{3} \mathrm{~B}$, detected at $25^{\circ} \mathrm{C}$ in toluene; $\lambda_{\mathrm{ex}}=410 \mathrm{~nm} ; \lambda$ detec $=664 \mathrm{~nm}$. Fit function, $F(t)$ : convolution of instrumental response function (exp.) (IRF) and decay function .

$$
F(t)=f_{\text {offset }}+g \int_{-\infty}^{t} I R F\left(t^{\prime}\right)\left[A_{1} \exp \left(-t^{\prime}+t \beta\right) / \tau_{1}+A_{2} \exp \left(-t^{\prime}+t \beta\right) / \tau_{2}\right] d t^{\prime}
$$

Table S1. Experimental fit parameters obtained from fit function $F(t)$.

\begin{tabular}{cccccc}
\hline & $A_{1}$ & $A_{2}$ & $A_{3}$ & $\tau_{1}(\mathrm{~ns})$ & $\tau_{2}(\mathrm{~ns})$ \\
\hline $\mathrm{P}_{\mathrm{zn}} \mathrm{T}$ & -40.906 & 6.135 & 34.771 & 1.2359 & 0.3155 \\
$\mathrm{P}_{\mathrm{zn}} \mathrm{T} \cdot \mathrm{Py}_{3} \mathrm{~B}$ & -11.0221 & 3.0536 & 7.9685 & 1.0203 & 0.339 \\
\hline
\end{tabular}




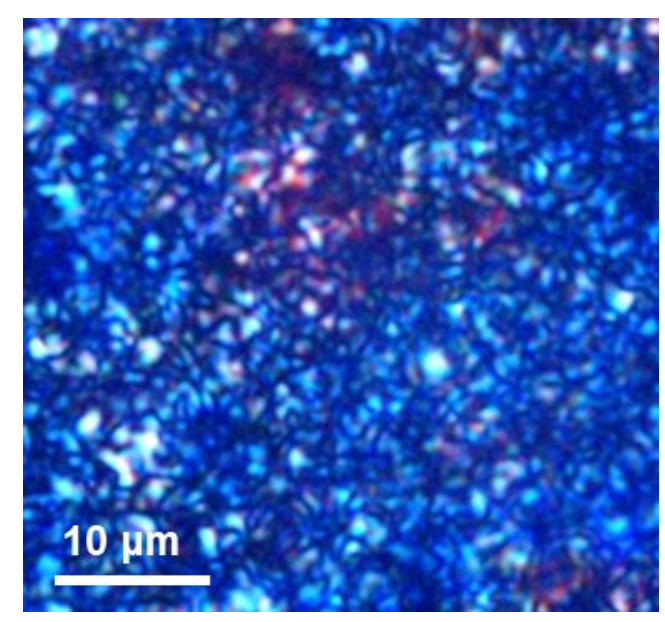

Figure S9. Polarized microscopic images of the bundled fibrous assemblies obtained from a $35 \%$ n-hexane containing toluene solution of $\mathrm{P}_{\mathrm{Zn}} \mathrm{T} \cdot \mathrm{Py}_{3} \mathrm{~B}$. 